\title{
Hardening and Optimizing of the Black Gold Thin Film as the Absorption Layer for Infrared Detector
}

\author{
Dong-pei Qian, Chuan-gui Wu, Yao Shuai, Wen-bo Luo, Qiang-xiang Peng, \\ Xiao-yong Chen, Wan-li Zhang \\ State Key Laboratory of Electronic Thin Films and Integrated Devices, \\ University of Electronic Science and Technology of China, Chengdu, China \\ Email: 227776161@qq.com
}

Received 2013

\begin{abstract}
This paper reports on the study of the black gold thin film as the absorption layer in the near infrared spectrum. The fabrication of the black gold thin film was achieved by a thermal evaporation technique in $\mathrm{N}_{2}$ atmosphere. Different evaporation conditions were attempted to optimize the absorbance of the black gold coating, especially the atmosphere pressure and the mass of evaporation source. The long-standing problem of black gold's adhesion with the substrate was solved by fuming 502 superglues into the black gold layer, which had almost no impact on the absorbance performance. Layers produced at $\mathrm{N}_{2}$ atmosphere of $3 \times 10^{3}$ Pa show an absorbance exceeding 0.9 in the near infrared.
\end{abstract}

Keywords: Black Gold; 502 Fuming; Absorption Layer

\section{Introduction}

An absorption layer is an indispensable part of a highperformance infrared detector for transforming infrared radiation into heat $[1,2]$. For high frequency application, the radiation absorption layer requires small heat capacity and high absorbance to achieve maximal sensitivity and minimal response time. Consequently, infrared absorbing lacquers or printing ink [3] may not be the best option as for their large masses and correspondingly high heat capacitance while black gold coating is preferred due to its thin thickness and therefore, low heat capacity.

In this paper, the absorbance of black gold will be mainly investigated. Black gold has been criticized for its rigidity and its weak adhesion with the substrate. In this paper, 502 superglues will be fumed into the black gold layer to harden the black gold coating [4]. And the absorbance will be tested to see if the absorbance is affected by this method. Further measurements will aim at the detailed relations between the evaporation conditions (like the pressures of $\mathrm{N}_{2}$ atmosphere, masses of gold) and the absorbance. Considering the heat capacitance, the high absorbance in the near-infrared region should be achieved under the condition of keeping the mass of evaporation source as low as possible.

\section{Experimental}

\subsection{Fabrication of Black Gold and Study of Its Influencing Factors}

We used the thermal resistance coating machine (MN-
300 ) as the thermal evaporator. Firstly, pure gold granules were laid in a dip in the middle of a molybdenum foil with width of $10 \mathrm{~mm}$ and thickness of $0.3 \mathrm{~mm}$, and one sample was attached to a copper block mounted on the cylinder which is $5 \mathrm{~cm}$ above the evaporation source. Then, the vacuum chamber was evacuated just by a mechanical pump to a pressure of $1 \mathrm{~Pa}$ for around $1 \mathrm{~h}$ before nitrogen gas was introduced up to a pressure of $10^{4} \mathrm{~Pa}$. This pressure lasted for 5 min to reduce the content of oxygen which is known to lower the absorbance [2]. After the rinsing, the pressure was adjusted to evaporation pressure $\left(1.5 \times 10^{2} \mathrm{~Pa}, 1.8 \times 10^{2} \mathrm{~Pa}, 2 \times 10^{2} \mathrm{~Pa}, 2.5 \times 10^{2}\right.$ $\mathrm{Pa}, 3 \times 10^{2} \mathrm{~Pa}, 5 \times 10^{2} \mathrm{~Pa}, 1 \times 10^{3} \mathrm{~Pa}, 2 \times 10^{3} \mathrm{~Pa}, 3 \times 10^{3}$ Pa) to start the film coating. $150 \mathrm{~A}$ current was applied to meet the requirement of 0.5 to $3.3 \mathrm{mg} / \mathrm{s}$ evaporation rate. And Evaporation time depends on the mass of gold $(0.1 \mathrm{~g}$, $0.2 \mathrm{~g}, 0.3 \mathrm{~g})$.

Different pressures of nitrogen atmosphere and different masses of gold granules were attempted as variables to explore their influences on the absorbance of the black gold coatings, which were tested by Fourier transform infrared spectroscopy.

\subsection{Fuming and Its Influence on Absorbance}

A 502 fingerprint fuming cabinet (BTSP-II) is available in our laboratory. To begin with, a cup of water was placed on one heater, 4.5 gram 502 superglues were loaded in an aluminum foil dish on another heater and the sample was suspended $30 \mathrm{~cm}$ above the heater with the black gold 
coating facing the aluminum foil dish. After that, the whole fuming procedure was automatically following the timer order which was set before. Specifically, the humidification lasted for 25 min to reach the humidity of $80 \%$ $\mathrm{RH}$ in the cabinet, and then the evaporation of glues continued for $30 \mathrm{~min}$. At last, another $20 \mathrm{~min}$ was taken to make sure that 502 glues filled sufficiently into black gold coating.

The absorbance of the black gold film after 502 fuming was tested to make a comparison with the raw black gold film.

\section{Results and Discussion}

The near-infrared reflectivity $(\mathrm{R})$ measurements of the black gold are performed using a Fourier transform infrared spectroscopy. As the black gold thin film is deposited on the non-transparent substrate, absorbance A of the film can be calculated by $\mathrm{A}=1-\mathrm{R}$ [2].

\subsection{Absorbance Properties of Black Gold Layers Prepared at Various N2 Pressures}

As seen in Figure 1, the reflectivity of the black gold layer is reduced with increasing pressure. Layers produced at $\mathrm{N}_{2}$ atmosphere of $3 \times 10^{3} \mathrm{~Pa}$ show an absorbance higher than 0.9 at wavelength below $8 \mu \mathrm{m}$ and exceeding 0.8 at wavelength below $15 \mu \mathrm{m}$. A higher $\mathrm{N}_{2}$ atmosphere pressure requires a closer distance between the sample and the evaporation source, where most of the materials cannot sustain under such a high temperature. Hence, $\mathrm{N}_{2}$ atmosphere pressure of $3 \times 10^{3} \mathrm{~Pa}$ is an optimal choice.

\subsection{Absorbance Properties of Black Gold Layers Prepared Consuming Different Masses of Evaporation Sources}

Three samples were prepared consuming evaporation sources of $0.3 \mathrm{~g}, 0.2 \mathrm{~g}$, and $0.1 \mathrm{~g}$ at $\mathrm{N}_{2}$ atmosphere pressure

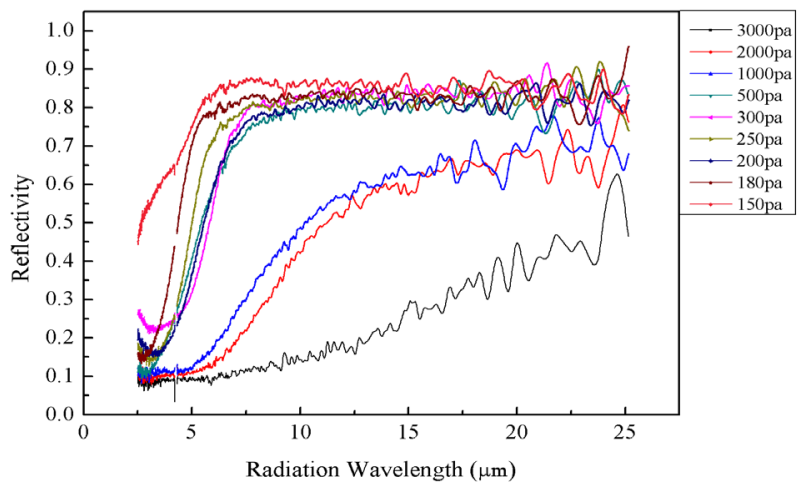

Figure 1. Reflectivity of black gold in various $\mathbf{N}_{2}$ atmospheres with same amount of source. of $3 \times 10^{3} \mathrm{~Pa}$, corresponding to the thickness of the black gold layer of $900 \mathrm{~nm}, 400 \mathrm{~nm}$, and $200 \mathrm{~nm}$ respectively. As we can see from the Figure 2, the sample with evaporation source of $0.3 \mathrm{~g}$ gold granules exhibits a higher absorbance than others at wavelength above $7 \mu \mathrm{m}$, but lower at wavelength below $6 \mu \mathrm{m}$. As a whole, the black gold coating consuming evaporation source of $0.3 \mathrm{~g}$ exhibits better absorbance performance in wider range of the near-infrared spectrum. On top of that, the less gold used, the thinner film is, correspondingly a lower heat capacity obtained, which is directly related to heat response time.

\subsection{Absorbance Property after 502 Fuming}

Figure 3 illustrates two curves of reflectivity in almost similar tracks. We can see that the reflectivity of black

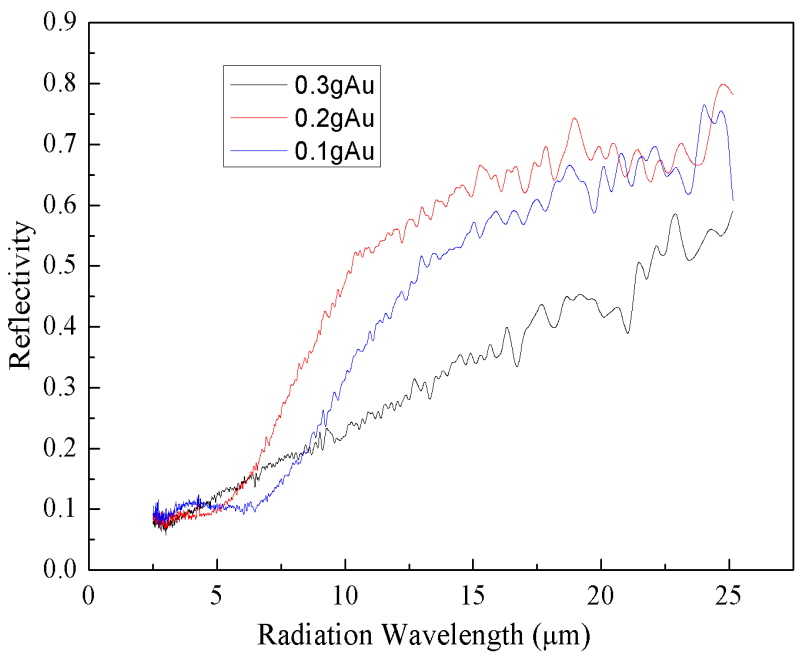

Figure 2. Reflectivity of black gold with different amount of source at same $N_{2}$ pressure of 3000 pa.

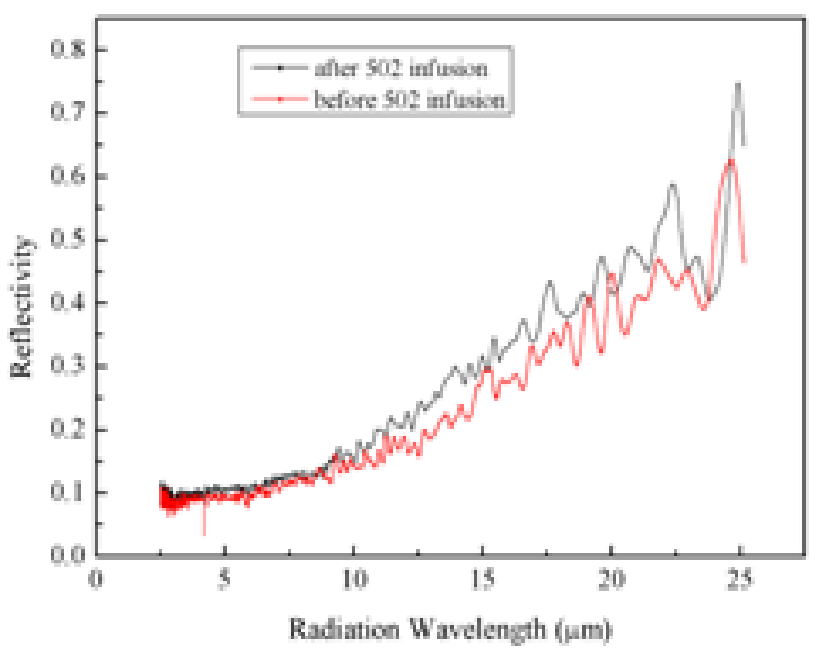

Figure 3. Reflectivity of black gold both before and after 502 fuming at $\mathrm{N}_{2}$ pressure of 3000 pa. 
gold after 502 infusion increases just marginally. It indicates that the 502 superglues fuming method does not obviously influence the absorbance performance of the black gold coating. Additionally, the black gold coating after the fuming is extraordinarily strong and can barely be scraped off.

\section{Conclusions}

Under the condition of $\mathrm{N}_{2}$ atmosphere pressure of $3 \times 10^{3}$ $\mathrm{Pa}$ and evaporation source of $0.3 \mathrm{~g}$, the absorbance of the black gold coating deposited meets the requirement for the application in the near-infrared spectrum. More evaporation sources can be consumed to achieve a higher absorbance though the black gold coating will be thicker, resulting in a higher response time of the infrared detector. The method of fuming 502 superglues to reinforce the adhesion between the black gold layer and the substrate is proved to be a viable method.

\section{Acknowledgements}

This work has been supported by the National Natural Science Foundation of China (NSFC. 51102037) and the Fundamental Research Funds for the Central Universities from UESTC (No. ZYGX2010J030).

\section{REFERENCES}

[1] T. W. Lang, K. Kühl and H. Sandmaier, “Absorbing Layers for Thermal Infrared Detectors," Sensors And Actuators A:Physical, Vol. 34, No. 3, 1992, pp. 243-248. doi:10.1016/0924-4247(92)85007-O

[2] W. Becker, et al., "Black Gold Deposits As Absorbers for Far Infrared Radiation,” Physica status solidi(b), Vol. 194, No. 1, 1996, pp. 241-255. doi:10.1002/pssb.2221940123

[3] P. Fiorentin, "Response of Printing Coloured Ink to Light Exposure Measurement and Analysis,” I2MTC, 2011, pp. 10-12.

[4] J. W. Cleary, R. E. Peale, M. Ishigami, et al., "Effects of Polymer Infusion and Characteristic Length Scale on Gold-Black Long-Wave and Far-infrared Absorbance," Materials Science and Engineering, Vol. 5, 2011, pp. 171-176. 